maximum lifts were studied. The electrical signal of the muscles (EMG) was recorded using a multichannel recorder (Sensor medic R 612; The Netherlands). The signal conditioning was made through a couple (direct/average EMG type 9852A), preamplifier (type 820) and amplifier (type 412). The gain of amplification was selected according to the level of activity of the particular muscle. The activity of the LD was for a long duration in phase I and II for both the Olympic lifts. In 2nd phase of C \& J there was $100 \%$ activity at all loads. In 3rd and 4th phase the duration of activity came down remarkably. Duration of activity of PM was very short in phases II and IV for both the Olympic lifts. Second and 3rd phase showed considerably long duration. In phase V, the activity was moderate for C \& J. Study shows remarkably high electrical activity of LD in phase I of both the lifts and in phase II it was maintained. PM showed very short response in all the phases especially in phase I and IV where it was considerably short. The pattern of electrical activity at all loads and in all the phase was identical.

\title{
93 MUSCLE ACTIVITY PATTERN IN OLYMPIC LIFTING: LATISSIMUS DORSI AND PECTORALIS MAJOR - AN EMG STUDY
}

Mohan C Narayana Deputy Director, Sports Authority of Andhra Pradesh, Hyderabad, Andhra Pradesh, India

10.1136/bjsm.2010.078725.93

An electromyography study was conducted to identify the response of latissimus dorsi (LD) and pectoralis major (PM) during the Olympic style of weightlifting, that is, two types of lifting were included in the study. 'Snatch' and 'Clean \& Jerk' in various loads from $20 \mathrm{~kg}, 40 \%, 60 \%$ and $80 \%$ of lifter's 